\title{
Health System Delay in the Treatment of Tuberculosis Patients in Ethiopia: A Systematic Review and Meta-analysis
}

\author{
Kenaw Tegegne Tefera ${ }^{1, ~ *}$, Fasil Wagnew ${ }^{2}$, Yihalem Abebe Belay ${ }^{1}$, Dawit Eyayu ${ }^{1}$, \\ Daniel Bekele Ketema ${ }^{1}$ \\ ${ }^{1}$ Department of Public Health, College of Health Science, Debre Markos University, Debre Markos, Ethiopia \\ ${ }^{2}$ Department of Pediatrics and Child Health Nursing, College of Health Science, Debre Markos University, Debre Markos, Ethiopia
}

Email address:

kenawtegegne@gmail.com (K. T. Tefera), fasil.n@gmail.com (F. Wagnew), yih2000ho@gmail.com (Y. A. Belay),

44dawit@gmail.com (D. Eyayu), dabekle121@gmail.com (D. B. Ketema)

*Corresponding author

\section{To cite this article:}

Kenaw Tegegne Tefera, Fasil Wagnew, Yihalem Abebe Belay, Dawit Eyayu, Daniel Bekele Ketema. Health System Delay in the Treatment of Tuberculosis Patients in Ethiopia: A Systematic Review and Meta-analysis. American Journal of Laboratory Medicine.

Vol. 6, No. 4, 2021, pp. 42-57. doi: 10.11648/j.ajlm.20210604.11

Received: May 10, 2021; Accepted: July 5, 2021; Published: July 13, 2021

\begin{abstract}
Delay in diagnosis and initiation of effective treatment associated with an increase in morbidity, mortality, and ongoing person-to-person transmission in the community at large. Several studies have been conducted in Ethiopia; however, studies assessing the health system's delay in treating tuberculosis patients have yielded inconsistent and inconclusive results. Therefore, this systematic review and meta-analysis aimed to determine the pooled median time of the health system delay in the treatment of tuberculosis and its determinants in Ethiopia. We systematically searched different databases: Google Scholar, Science Direct, PubMed, Embase, Scopus, and Springer link databases for studies published from June 6,1997 up to December 20, 2020. The quality of the studies was assessed using the Newcastle-Ottawa scale adapted for observational studies. We conducted a meta-analysis for the pooled median time of health system delay and its determinants using a random-effects model in $\mathrm{R}$ version 4.0.3 software (for median estimation) and Stata version 14 (for metan). A total of 14 studies with 6161 patients who met predetermined criteria were included. Our meta-analysis showed that the estimated pooled median time of the health system delay was 15.29 (95\%CI: 9.94-20.64) days. In the subgroup analysis, studies conducted from 1997 to 2015, the pooled median health system delay was 21.63 (95\% CI: 14.38-28.88) days, whereas in studies conducted after 2015, the pooled median time was 9.33 (95\% CI: 3.95-14.70) days. Living in rural areas (pooled OR: 2.42, 95\%CI: 1.16-5.02) was significantly associated with health system delay. In Ethiopia, this review highlights that patients were delayed more than two weeks in the treatment of tuberculosis. Being a rural resident, was the contributing factor of health system delay. For successful TB control, implementing efforts like providing regular health education to the community about TB emphasizes the rural community and enhancing the quality of care in TB treatment facilities in rural areas could have important implications to reduce health system delay.
\end{abstract}

Keywords: Health System Delay, Median, Meta-analysis, Tuberculosis, Ethiopia

\section{Introduction}

Despite remarkable progress in TB control that has been achieved over the past year, it remains a global public health challenge [1]. About one-fourth of the world's population were affected by Latent Tuberculosis (TB) and TB is the first infectious disease killer [2]. In 2019, an estimated 1.2 million people die due to tuberculosis, including 208000 HIVpositive people [3]. It kills more than five thousand children, women, and men each day $[1,4]$. In addition, globally, $3.3 \%$ of new TB cases and $17.7 \%$ of previously treated cases were assumed to harbor drug resistant-TB [3]. According to the 2020 Global tuberculosis report, Ethiopia is among the 30 high TB, HIV, and MDR-TB burden countries, with an 
annual estimated TB incidence of $140 / 100,000$ populations, and HIV negative TB mortality rate of 19 per 100,000 populations [3]. Despite this, with a timely diagnosis and appropriate treatment, most people who develop TB can be cured and avert millions of deaths each year, but there are still enormous gaps, notably in the detection and treatment of tuberculosis $[5,6]$.

Delay can be categorized as patient delay, health system delay (diagnostic and treatment delay), and total delay as the sum of patient delay and health system delay [7]. The majority of Ethiopian studies on health system delay [8-11] and a country assessment done in 2016, as well as the WHO 2006 report, defined health system delay as the interval from the first visit to a health care provider to the initiation of effective treatment and usually used the median value to categorize TB patients as delayed or not delayed $[12,13]$. Delay in diagnosis and treatment causes patients to be more likely to have advanced disease, complications, mortality, and increase ongoing person-to-person transmission in the community at large [14-18]. It has been estimated that a patient with untreated smear-positive pulmonary TB may infect, on average more than 10 patients annually and over 20 during the natural course of the untreated disease until death [1]. This means that rapid diagnosis and early treatment initiation are fundamental to reducing transmission, morbidity and mortality of tuberculosis patients [6]. Thus, determining the extent of delay and identifying the factors that correlate with different types of delay can aid tuberculosis control programs and help medical providers improve diagnosis and treatment efforts [19].

Health care system delay is a larger issue than patient delay, and it continues to be a major barrier to TB control [20, 21]. The time between TB diagnosis and treatment initiation has remained unacceptably long, particularly in high-burden countries $[22,23]$. A systematic review and meta-analysis showed that the median health system delay ranged from 2 to 87 days for low-income countries [24]. In high-income countries (HICs), the shortest period was 7.2 days in Japan [25] and the longest was 33 days in Norway [19]. In low- and middle-income countries (LMICs), it varies from 7 days in Vietnam [26] to 128.5 days in Afghanistan [27]. The median health system delay in Sub-Saharan Africa ranged from 2 days in Zimbabwe [28] to 77 days in Uganda [29].

According to $\mathrm{WHO}$, factors related to delay in $\mathrm{TB}$ diagnosis and treatment can be divided into three levels: socio-economic, clinical, and health system factors [30]. HIV, extra pulmonary tuberculosis, rural residence, visiting private practitioners or traditional medicine, old age, poverty, alcoholism, and substance abuse are the main factors associated with health system delays [23, 31, 32]. Health care facility related factors such as lack of diagnostic modalities, availability of trained staff, and lack of effective supervision were significantly associated with health system delay [20, $33,34]$. In addition, unemployment, labor migration, the number of providers that patients visit, and low income were also reported as factors of health system delay [21, 35, 36]. A systematic review and meta-analysis conducted in Sub-
Saharan African countries and the Middle East Asia showed that travel time for the return visit and being female was associated with health system delay $[37,38]$.

Massive efforts were implemented during the era of the stop TB strategy to substantially reduce the global burden of TB by 2015 through universal access to diagnosis and treatment regardless of socio-economic barriers. However, the health system's delay remains a major impediment to effective TB prevention and control [39]. Several studies have reported health system delays and its associated factors among TB patients in Ethiopia; however, the findings on health system delays have varied or been inconsistent and inconclusive. With these variations of reports, and as far as in our search, we could not find any studies conducted on systematic review and meta- analysis on the extent and associated factors of health system delay in Ethiopia. Therefore, this systematic review and meta-analysis aimed to provide a pooled national estimate of the median time of health system delay and to identify its associated factors in Ethiopia. This evidence will be helpful for healthcare professionals, health-policy makers, and program managers to apply efficient interventions, and to improve effective tuberculosis control programs.

\section{Methods}

\subsection{Reporting}

The Preferred Reporting Items for Systematic Reviews and Meta-analyses (PRISMA) guideline [40] was used to report the results of this systematic review and meta-analyses. This systematic review and meta-analysis was registered with PROSPERO Registration number CRD42020220820.

\subsection{Study Design and Setting}

We systematically reviewed studies conducted in Ethiopia aimed to estimate the pooled median time and to identify factors contributing to the health system delay in the treatment of tuberculosis. Ethiopia, subdivided into ten national regional states: namely, Amhara, Tigray, Oromia, Afar, Benishangul-Gumuz, Somali, Southern Nations Nationalities and People Region (SNNPR), Sidama, Gambella, Harari, and two city administrative states (Dire Dawa city council and Addis Ababa city administration) [41].

\subsection{Inclusion and Exclusion Criteria}

\subsubsection{Inclusion Criteria}

The studies were included if they met the following inclusion criteria:

Study design: All observational studies (cohort, casecontrol, and cross-sectional studies)

Study setting: Studies were conducted in Ethiopia.

Study participants: All tuberculosis patients above 15 years old.

Outcome: The outcome of interest was the median time of the health system delay for TB treatment.

Publication status: Studies in the English language, both 
published and unpublished.

Publication date: The authors included articles published from June 6, 1997 until December $20^{\text {th }}, 2020$.

Exclusion criteria: Despite the above-mentioned eligibility criteria, articles which we were unable to access the full text after two email contacts with the principal investigator of the particular study were excluded from the analysis.

Studies done before 1997 were excluded from the review since Ethiopia launched the Directly Observed Treatment, Short-Course (DOTs) strategy in 1997 as part of the National Tuberculosis and Leprosy Control Program (TLCP) to treat TB patients [1]. WHO developed DOTS strategies to address major constraints on the achievement of global TB control targets. One of the strategies was expanding access to diagnosis and treatment through community TB care and public-private mix approaches aimed at engaging all care providers in DOTS implementation [39]. This might have an impact on reducing the number of days for the initiation of tuberculosis treatment.

\subsubsection{Databases and Search Strategy}

The comprehensive search for potential studies were conducted by two of the authors (KT and FW). The studies were published in English from June 6, 1997 up to December 20, 2020. We exhaustively searched the following databases: Google Scholar, Science Direct, PubMed, Embase, Scopus, and Springer link databases for all available studies using the search strategy by combining the keywords, Medical Subject Heading (MeSH) and free text terms described in (Table 3). In addition, the manual search of reference list of included studies were also reviewed to retrieve further studies. The titles and abstracts of the identified reports were used to exclude studies that did not meet the inclusion criteria in the first step. In the next step, for studies potentially eligible for inclusion, both authors (KT and FW) selected full-text studies based on eligibility criteria independently. The full articles of selected studies were screened to confirm eligibility and the reviewers discussed whether the studies should be included until a consensus was reached. If not, the disagreement was resolved by the decision of the third coauthor (DE). To identify unpublished and ongoing studies, we contacted researchers and experts in the TB field. We also requested unpublished data from organizations such as the Federal Ministry of Health, Government of Ethiopia), and Non-governmental organizations (NGOs) working on tuberculosis, but no one responded.

\subsubsection{Outcome Measures and Data Extraction}

The outcome of interest in this study was health system delay in the treatment of tuberculosis, defined as the time between the first visit to a health care provider and the start of treatment [12, 42]. Therefore, included studies define operationally health system delay from the first visit to the health care facility to the initiation of treatment and report the median health system delay with the inter quartile range (IQR). All observational studies of patients receiving treatment for TB that recorded at least the median health system delay were included. We converted all time measures to days for studies that did not report delay measures in days. Delay reported in weeks were transformed into days by a multiple of 7 ; months by a multiple of 30 . We used the median and inter quartile range of studies as the primary measure for meta-analysis. Because, all the included studies reported a median number of days with an inter quartile range. Eligible studies were selected using the pre-specified inclusion/exclusion criteria. All relevant information from the included studies were extracted independently by two (KT and $\mathrm{FW}$ ) authors after data extraction checklist development. Two authors (KT, FW) screened titles and abstracts obtained from the database search and decided on eligibility. Following identification of potential studies, KT and FW made the final selection through review of full articles including the study design, participants, outcome variable, and publication year. Co-authors (DE and YAB) closely supervised the selection process. Finally, potentially eligible full-text articles that fulfilled the inclusion criteria were included in the review. We extracted data from each included study into a Microsoft excel spreadsheet: first authors, publication year, the region of the study conducted, data collection period, study participants, sample size, and the median with IQR of health system delay. We also extracted the predictor variables from the included studies for health system delay. Further data were also extracted on the health system delay among exposure categories and the odds ratio for the meta-analysis.

\subsection{Quality Assessment Tool}

Two reviewers (KT and FW) independently assessed the quality of the articles before including in the analysis. The Newcastle-Ottawa Scale (NOS) adapted for cross-sectional studies was used to assess the quality of the included studies $[43,44]$. The quality of each study was assessed in three sections using the following criteria: participant selection, comparability of the groups, and description of outcome assessment with a maximum of ten scores. A star was assigned to each point of the scale to categorize the studies into good, fair, and poor quality based on the NOS criteria. The first section scored a maximum of five stars and focused on the representativeness of the sample. The second section concerned with how the confounding variables were controlled with a maximum of two stars. The third section focuses on the study's outcomes and statistical analysis, with the possibility of earning three stars (Table 4). Finally, the average score provided by two reviewers was taken. A third author (DE) was brought in to resolve their disagreement over the assessment result. Articles with a score of seven or higher were considered to be of high quality. This cut-off point was considered after referring to previous literature [45].

\subsection{Data Processing and Analysis}

Data were extracted from each of the original studies using Microsoft Excel and then exported to STATA version 14 and $\mathrm{R}$ software version 4.0.3 for analysis. The pooled estimates 
with $95 \%$ confidence intervals (CI) were presented using forest plots. The pooled median health system delay (in days) was estimated using a random effect model. The heterogeneity of the included studies was evaluated using I squared statistic [46]. In this study, significant heterogeneity was observed among the included studies $\left(\mathrm{I}^{2}=99.88 \%, \mathrm{p}<\right.$ 0.0001). As a result, a random-effects meta-analysis model was used. The median time of health system delay from different studies was pooled in a meta-analysis using $\mathrm{R}$ software. We also conducted a meta-analysis on factors in health system delay in the treatment of TB using STATA version 14 statistical software. The overall effect of factors related to delays was estimated from studies by conducting a meta-analysis based on ORs and 95\% CI. Sub-group analysis was performed to identify potential factors that could explain the inconsistencies between effect sizes across the primary studies based on different variables (i.e., year of study, region of study conducted, sample size, and types of TB).

\section{Results}

\subsection{Search Results}

A total of 1031 articles were identified during our initial search from databases and all retrieved studies were exported to the Endnote version 9 (Clarivate, Thomson Reuters, George Mason University) reference manager and then 477 articles were excluded due to duplication. We excluded 692 articles after examining the titles and abstracts, primarily because they did not have a relationship with the outcome of interest. Full-text evaluations were performed on 48 studies; of which 34 studies were excluded after reading the full text with the reason (Table 5). Finally, a total of 14 studies that satisfied the eligibility criteria were included in this systematic review and meta-analysis (figure 1).

\subsection{Characteristics of Original Studies}

The included articles covered 9 regions with two city administrations; the majority of the studies were conducted in Amhara region [7, 11, 47-50]. Five studies [35, 50-53] enrolled pulmonary tuberculosis patients, three studies $[7,8$, 47] enrolled smear-positive PTB patients, and the remaining six studies [9-11, 48, 49, 54] enrolled both types of tuberculosis patients. All of the articles were cross-sectional studies, and the sample sizes of the individual studies included in our meta-analysis ranged from $129[35]$ to 875 [51] with a total of 6161 study participants. The studies included in this review were published between 2003 and 2019 (Table 1).

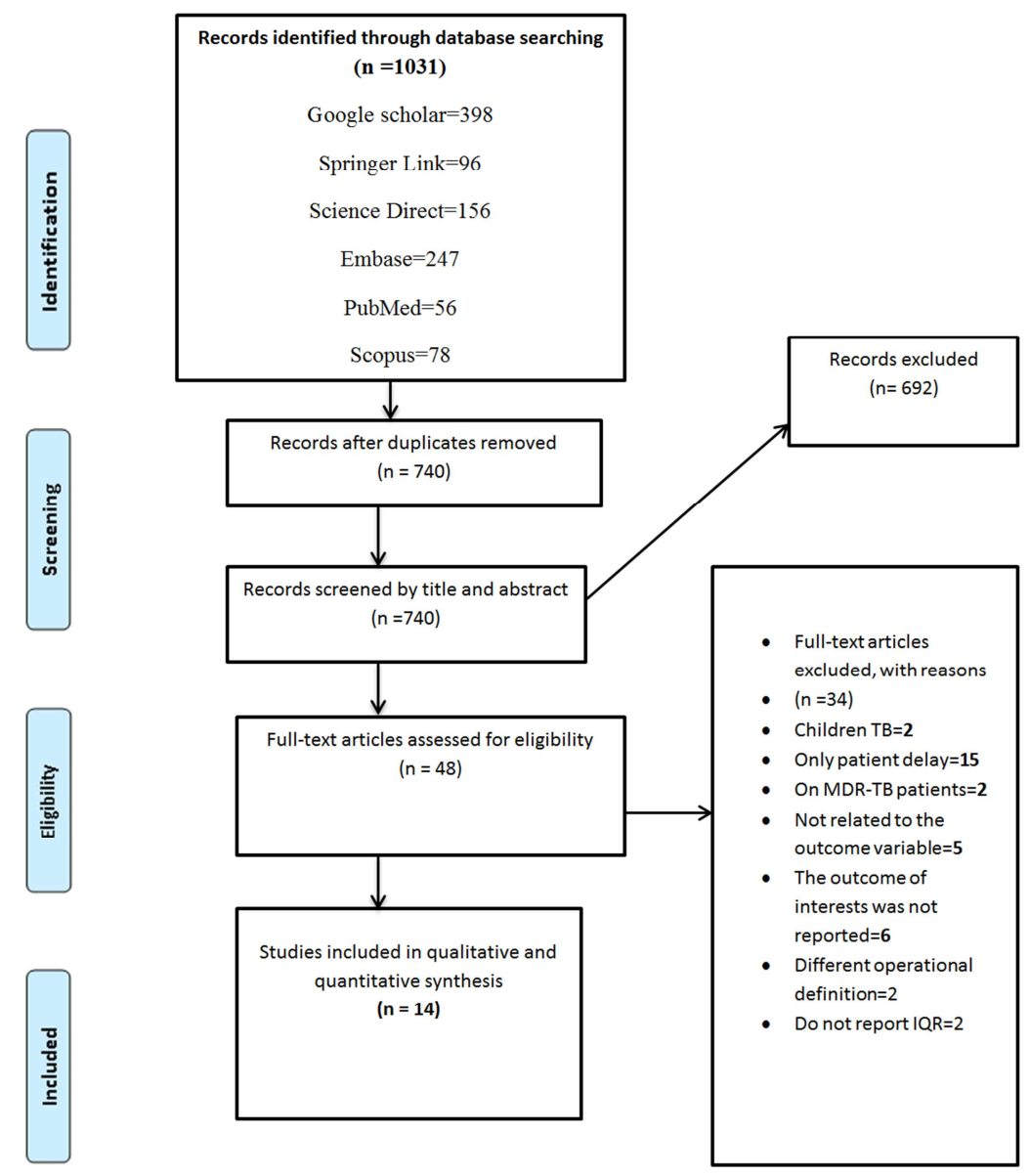

Figure 1. Flow diagram describing the selection of studies included in the systematic review and meta-analysis of health system delay among tuberculosis patients in Ethiopia. 
Table 1. Characteristics of included studies conducted in Ethiopia on health system delay in Tuberculosis patients ( $n=14)$.

\begin{tabular}{|c|c|c|c|c|c|c|c|c|}
\hline Author & Year of study & region & Study area & Study design & Sample size & $\begin{array}{l}\text { HS delay (Median } \\
\text { with IQR) }\end{array}$ & Participants & Study quality \\
\hline Ayalew et al & 2018 & Amhara & both & $\mathrm{CS}$ & 300 & $4(3-5)$ & ЕРТВ \&PTВ & high \\
\hline Belay et al & 2010 & Afar & both & $\mathrm{CS}$ & 216 & 33.5 & ЕРТВ \&РТВ & high \\
\hline Gebregizaber et al & 2014 & Amhara & both & $\mathrm{CS}$ & 706 & $22(4-88)$ & PTB & low \\
\hline Yimer et la & 2010 & Amhara & hospital & $\mathrm{CS}$ & 201 & $27(8-60)$ & ЕРТВ \&РТВ & high \\
\hline Asefa et la & 2012 & SNNPR & $\mathrm{HC}$ & $\mathrm{CS}$ & 328 & $11(7-18)$ & Smear +ve PTB & high \\
\hline Hussen et al & 2011 & Oromia & both & $\mathrm{CS}$ & 129 & $34(8-105)$ & PTB & high \\
\hline Adenager et al & 2012 & AA & both & $\mathrm{CS}$ & 425 & $9(3-29)$ & PTB & high \\
\hline Seid et al & 2017 & Amhara & both & $\mathrm{CS}$ & 382 & $6(4-8)$ & ЕРТВ\&РТВ & high \\
\hline Tedla et al & 2019 & Tigray & both & $\mathrm{CS}$ & 875 & $18(2-72)$ & PTB & low \\
\hline Haboro et al & 2017 & SNNPR & both & $\mathrm{CS}$ & 340 & $5(4-85)$ & РTB & high \\
\hline Asres et al & 2016 & SNNPR & both & $\mathrm{CS}$ & 735 & $22(9-48)$ & ЕРТВ\&РТВ & high \\
\hline yimer et al & 2003 & Amhara & both & $\mathrm{CS}$ & 384 & $21(7-60)$ & Smear +ve PTB & high \\
\hline Datiko et al & 2017 & All regions & $\mathrm{HC}$ & $\mathrm{CS}$ & 844 & $6(3-15)$ & ЕРТВ \&РТВ & low \\
\hline Bogale et al & 2016 & Amhara & both & $\mathrm{CS}$ & 296 & $5(4-7)$ & Smear +ve PTB & high \\
\hline
\end{tabular}

$\mathrm{HS}=$ health system, IQR=Inter quartile range, $\mathrm{EPTB}=$ Extra pulmonary tuberculosis, $\mathrm{PTB}=$ pulmonary tuberculosis, $\mathrm{HC}=$ health center, both=both hospital and health center, $\mathrm{CS}=$ Cross sectional study

$\mathrm{SNNPR}=$ Southern nations nationalities and peoples' region, $\mathrm{AA}=\mathrm{Addis} \mathrm{Ababa}$

\subsection{Meta-analysis}

The smallest median health system delay among studies included in the analysis was 4 days [11] and the longest was 34 days [35]. The overall estimated pooled median health system delay was 15.29 (95\% CI: 9.94-20.64) days. We used a random-effect model because the overall results of the I squared statistic shown high heterogeneity among included studies $\left(\mathrm{I}^{2}=99.88 \%\right)$ for median health system delay estimation. Therefore, we conducted subgroup analysis through sample size, year of study, region of the study conducted, and type of tuberculosis in order to explore possible causes of heterogeneity.

Table 2. Sub group Analysis of studies included in meta-analysis on health system delay in the treatment of tuberculosis patients ( $n=14$ ).

\begin{tabular}{|c|c|c|c|c|}
\hline subgroup & Number of included studies & Random effects $(95 \% \mathrm{CI})$ & Test of Heterogeneity $\left(I^{2}\right)$ & P-value \\
\hline \multicolumn{5}{|l|}{ By year of study } \\
\hline $1997-2015$ & 7 & $21.63(14.38-28.88)$ & $97.35 \%$ & $<0.0001$ \\
\hline After 2015 & 7 & $9.33(3.95-14.70)$ & $99.89 \%$ & $<0.0001$ \\
\hline \multicolumn{5}{|l|}{ By Region } \\
\hline Amhara & 6 & $13.84(5.69-21.98)$ & $99.94 \%$ & $<0.0001$ \\
\hline SNNP & 3 & $12.68(2.98-22.37)$ & $98.38 \%$ & $<0.0001$ \\
\hline others & 5 & $19.27(7.92-30.62)$ & $99.06 \%$ & $<0.0001$ \\
\hline All form of TB & 6 & $16.01(6.02-26.01)$ & $99.94 \%$ & $<0.0001$ \\
\hline PTB & 5 & $16.63(7.46-25.81)$ & $97.09 \%$ & $<0.0001$ \\
\hline $\begin{array}{l}\text { Smear +ve PTB } \\
\text { by sample size }\end{array}$ & 3 & $12.14(3.13-21.15)$ & $99.51 \%$ & $<0.0001$ \\
\hline Less than 350 & 7 & $16.34(6.33-26.34)$ & $99.94 \%$ & $<0.0001$ \\
\hline Greater than 350 & 7 & $14.65(9.03-20.28)$ & $99.35 \%$ & $<0.0001$ \\
\hline
\end{tabular}

Others: Afar, Oromia, Addis Ababa, Tigray (only one study reported from each region)

Table 3. Search terms and strategy.

\begin{tabular}{|c|c|c|}
\hline Databases & Search terms and strategy & Number of studies \\
\hline PubMed & $\begin{array}{l}\text { ("patients"[MeSH Terms] OR "patient*"[Text Word]) AND ("Delayed Diagnosis"[MeSH Terms] OR } \\
\text { "diagnostic delay*"[Text Word] OR "Time-to-Treatment"[MeSH Terms] OR "treatment delay*"[Text Word] } \\
\text { OR "patient delay*"[Text Word] OR "health system delay*"[Text Word] OR "health service delay*"[Text } \\
\text { Word] OR "provider delay*"[Text Word] OR "doctors delay*"[Text Word] OR "total delay*"[Text Word]) } \\
\text { AND ("tuberculosis"[MeSH Terms] OR "tuberculosis*"[Text Word] OR "pulmonary tuberculosis*"[Text } \\
\text { Word]) AND ("Ethiopia"[MeSH Terms] OR "Ethiopia*"[Text Word]) } \\
\text { \#2 AND \#3 AND \#4 AND \#6 }\end{array}$ & 56 \\
\hline $\begin{array}{l}\text { Google } \\
\text { scholar }\end{array}$ & $\begin{array}{l}\text { Patient* AND "diagnostic delay*" OR "treatment delay*” OR "patient delay*” OR "health system delay*" OR } \\
\text { "health service delay*” OR "provider delay*" OR "total delay*" AND tuberculosis* OR "pulmonary } \\
\text { tuberculosis*" OR AND "associated factor*" OR determinant* AND Ethiopia* }\end{array}$ & 398 \\
\hline $\begin{array}{l}\text { Science } \\
\text { direct }\end{array}$ & $\begin{array}{l}\text { "diagnostic delay" OR "treatment delay" OR "health system delay" OR "total delay" AND tuberculosis OR } \\
\text { "pulmonary tuberculosis" AND "associated factor" AND Ethiopia }\end{array}$ & 156 \\
\hline
\end{tabular}




\begin{tabular}{llc}
\hline Databases & Search terms and strategy & Number of studies \\
\hline \multirow{2}{*}{ Scopus } & $\begin{array}{l}\text { patient* AND "diagnostic delay*" OR "treatment delay*" OR "patient delay*" OR "health system delay*" OR } \\
\text { "health service delay*" OR "provider delay*" OR "total delay*" AND tuberculosis* OR "pulmonary } \\
\text { tuberculosis*" AND "associated factor*" OR determinant* AND Ethiopia* }\end{array}$ & 78 \\
$\begin{array}{l}\text { Springer } \\
\text { link }\end{array}$ & $\begin{array}{l}\text { Patient* AND "diagnostic delay*” OR "treatment delay*” OR "patient delay*” OR "health system delay*” OR } \\
\text { "health service delay*" OR "provider delay*” OR "total delay*” AND tuberculosis* OR "pulmonary } \\
\text { tuberculosis*” AND "associated factor*” OR determinant* AND Ethiopia* }\end{array}$ & 96 \\
\hline
\end{tabular}

Table 4. Quality assessment result of the studies included in the systematic review and meta-analysis (Newcastle-Ottawa quality assessment scale) for CrossSectional Studies.

\begin{tabular}{|c|c|c|c|c|}
\hline Author/year & Study design & Selection & Comparability & Outcome \\
\hline Ayalew et al/2018 & $\mathrm{CS}$ & $* * *$ & $* *$ & $* * *$ \\
\hline Belay et al/2010 & CS & $* * * *$ & $* *$ & $* * *$ \\
\hline Gebreegizaber et al/2014 & $\mathrm{CS}$ & $* * *$ & $*$ & $* *$ \\
\hline Yimer et la/2010 & $\mathrm{CS}$ & $* * *$ & $* *$ & $* * *$ \\
\hline Asefa et al/2012 & $\mathrm{CS}$ & $* * * *$ & $* *$ & $* * *$ \\
\hline Hussen et al/2011 & $\mathrm{CS}$ & $* * *$ & $* *$ & $* * *$ \\
\hline Adenager et al/2012 & $\mathrm{CS}$ & $* * * *$ & $* *$ & $* * *$ \\
\hline Tedla et al/2019 & $\mathrm{CS}$ & $* * *$ & $*$ & $* *$ \\
\hline Haboro et al/2017 & CS & $* * * *$ & $* *$ & $* * *$ \\
\hline Asres et al/2016 & $\mathrm{CS}$ & $* * * *$ & $* *$ & $* *$ \\
\hline Yimer et al/2003 & $\mathrm{CS}$ & $* * *$ & $* *$ & $* * *$ \\
\hline Datiko et al/2017 & $\mathrm{CS}$ & $* * *$ & $*$ & $* *$ \\
\hline Bogale et al/2016 & $\mathrm{CS}$ & $* * *$ & $* *$ & $* * *$ \\
\hline
\end{tabular}

CS: refers to cross-sectional

Selection: scored a maximum of five stars

Comparability: scored a maximum of two stars

Outcome: scored a maximum of three stars

A score of $\geq 7$ out of 10 were considered as achieving high Quality

Table 5. List of excluded references and reasons for exclusion.

\begin{tabular}{|c|c|c|}
\hline No & excluded references & Reasons \\
\hline 1 & $\begin{array}{l}\text { Shiferaw MB, Zegeye AM. Delay in tuberculosis diagnosis and treatment in Amhara state, Ethiopia. BMC health services research. } \\
2019 ; 19 \text { (1): } 232 \text {. }\end{array}$ & 2 \\
\hline 2 & $\begin{array}{l}\text { Fuge TG, Bawore SG, Solomon DW, Hegana TY. Patient delay in seeking tuberculosis diagnosis and associated factors in Hadiya } \\
\text { Zone, Southern Ethiopia. BMC research notes. 2018; } 11 \text { (1): } 115 .\end{array}$ & 1 \\
\hline 3 & $\begin{array}{l}\text { Mesfin MM, Newell JN, Walley JD, Gessessew A, Madeley RJ. Delayed consultation among pulmonary tuberculosis patients: a cross } \\
\text { sectional study of } 10 \text { DOTS districts of Ethiopia. BMC Public Health. 2009; } 9 \text { (1): } 53 .\end{array}$ & 3 \\
\hline 4 & $\begin{array}{l}\text { Sorsa A, Jerene D, Negash S, Habtamu A. Use of Xpert Contributes to Accurate Diagnosis, Timely Initiation, and Rational Use of } \\
\text { Anti-TB Treatment Among Childhood Tuberculosis Cases in South Central Ethiopia. Pediatric Health, Medicine and Therapeutics. } \\
\text { 2020; 11: } 153 .\end{array}$ & 2 \\
\hline 5 & $\begin{array}{l}\text { Abdu M, Balchut A, Girma E, Mebratu W. Patient Delay in Initiating Tuberculosis Treatment and Associated Factors in Oromia } \\
\text { Special Zone, Amhara Region. Pulmonary medicine. 2020; } 2020 .\end{array}$ & 1 \\
\hline 6 & $\begin{array}{l}\text { Yimer SA, Holm - Hansen C, Storla DG, Bjune GA. Tuberculosis management time: an alternative parameter for measuring the } \\
\text { tuberculosis infectious pool. Tropical Medicine \& International Health. 2014; } 19 \text { (3): 313-20. }\end{array}$ & 1 \\
\hline 7 & $\begin{array}{l}\text { Mekonnen YA, Abebe L, Fentahun N, Belay SA, Kassa AW. Delay for first consultation and associated factors among tuberculosis } \\
\text { patients in Bahir Dar town administration, North West Ethiopia. American Journal of Health Research. 2014; } 2 \text { (4): 140-5. }\end{array}$ & 1 \\
\hline 9 & $\begin{array}{l}\text { Yimer SA, Norheim G, Namouchi A, Zegeye ED, Kinander W, Tønjum T, et al. Mycobacterium tuberculosis lineage } 7 \text { strains are } \\
\text { associated with prolonged patient delay in seeking treatment for pulmonary tuberculosis in Amhara Region, Ethiopia. Journal of } \\
\text { clinical microbiology. 2015; } 53 \text { (4): 1301-9. }\end{array}$ & 1 \\
\hline 10 & $\begin{array}{l}\text { Shiferaw MB, Yismaw G. Magnitude of delayed turnaround time of laboratory results in Amhara Public Health Institute, Bahir Dar, } \\
\text { Ethiopia. BMC health services research. } 2019 ; 19 \text { (1): } 240 \text {. }\end{array}$ & 3 \\
\hline 11 & $\begin{array}{l}\text { Tadesse T, Demissie M, Berhane Y, Kebede Y, Abebe M. Long distance travelling and financial burdens discourage tuberculosis } \\
\text { DOTs treatment initiation and compliance in Ethiopia: a qualitative study. BMC public health. 2013; } 13 \text { (1): } 424 \text {. }\end{array}$ & 3 \\
\hline 12 & $\begin{array}{l}\text { Ambaw F, Mayston R, Hanlon C, Alem A. Is depression associated with pathways to care and diagnosis delay in people with } \\
\text { tuberculosis in Ethiopia? Global Mental Health. } 2019 ; 6 \text {. }\end{array}$ & 1 \\
\hline 13 & $\begin{array}{l}\text { Getnet F, Demissie M, Worku A, Gobena T, Seyoum B, Tschopp R, et al. Determinants of Patient Delay in Diagnosis of Pulmonary } \\
\text { Tuberculosis in Somali Pastoralist Setting of Ethiopia: A Matched Case-Control Study. International journal of environmental } \\
\text { research and public health. 2019; } 16 \text { (18): } 3391 \text {. }\end{array}$ & 1 \\
\hline 14 & $\begin{array}{l}\text { Yirgu R, Lemessa F, Hirpa S, Alemayehu A, Klinkenberg E. Determinants of delayed care seeking for TB suggestive symptoms in } \\
\text { Seru district, Oromiya region, Ethiopia: a community based unmatched case-control study. BMC infectious diseases. } 2017 ; 17 \text { (1): } \\
292 .\end{array}$ & 1 \\
\hline
\end{tabular}




\begin{tabular}{|c|c|c|}
\hline No & excluded references & Reasons \\
\hline 15 & $\begin{array}{l}\text { Alema HB, Hailemariam SA, Misgina KH, Weldu MG, Gebregergis YS, Mekonen GK, et al. Health care seeking delay among } \\
\text { pulmonary tuberculosis patients in North West zone of Tigrai region, North Ethiopia. BMC infectious diseases. 2019; 19 (1). }\end{array}$ & 1 \\
\hline 16 & $\begin{array}{l}\text { Gebeyehu E, Azage M, Abeje G. Factors associated with patient's delay in tuberculosis treatment in Bahir Dar City administration, } \\
\text { Northwest Ethiopia. BioMed Research International. 2014; } 2014 \text {. }\end{array}$ & 1 \\
\hline 17 & $\begin{array}{l}\text { Hamza A, Ababa A. Delay in tuberculosis diagnosis among tuberculosis patients at the three hospitals: asella, robe and abomsa of } \\
\text { arsi zone, oromia regional state, March, 2015. Open Access Library Journal. 2015;2 (12): } 1\end{array}$ & 6 \\
\hline 18 & $\begin{array}{l}\text { Asres M, Gedefaw M, Kahsay A, Weldu Y. Patients' delay in seeking health care for tuberculosis diagnosis in East Gojjam zone, } \\
\text { Northwest Ethiopia. The American journal of tropical medicine and hygiene. } 2017 ; 96 \text { (5): 1071-5. }\end{array}$ & 1 \\
\hline 19 & $\begin{array}{l}\text { Madebo T, Lindtjorn B. Delay in treatment of pulmonary tuberculosis: an analysis of symptom duration among Ethiopian patients. } \\
\text { MedGenMed: Medscape general medicine. 1999: E6. }\end{array}$ & 3 \\
\hline 20 & $\begin{array}{l}\text { Mekonnen YA, Abebe L, Fentahun N, Belay SA, Kassa AW. Delay for first consultation and associated factors among tuberculosis } \\
\text { patients in Bahir Dar town administration, North West Ethiopia. American Journal of Health Research. 2014; } 2 \text { (4): 140-5. }\end{array}$ & 1 \\
\hline 21 & $\begin{array}{l}\text { Demissie M, Lindtjorn B, Berhane Y. Patient and health service delay in the diagnosis of pulmonary tuberculosis in Ethiopia. BMC } \\
\text { public health. 2002; } 2 \text { (1): } 23 \text {. }\end{array}$ & 6 \\
\hline 22 & $\begin{array}{l}\text { Ehlers VJ, Aragaw GS. An audit of diagnosis and treatment of tuberculosis in Ethiopia. African Journal of Primary Health Care \& } \\
\text { Family Medicine. 2014; } 6 \text { (1): 1-6. }\end{array}$ & 3 \\
\hline 23 & $\begin{array}{l}\text { Alene M, Assemie MA, Yismaw L, Gedif G, Ketema DB, Gietaneh W, et al. Patient delay in the diagnosis of tuberculosis in } \\
\text { Ethiopia: a systematic review and meta-analysis. BMC infectious diseases. } 2020 ; 20(1): 1-9 \text {. }\end{array}$ & 4 \\
\hline 24 & $\begin{array}{l}\text { Tefera KT, Mesfin N, Reta MM, Sisay MM, Tamirat KS, Akalu TY. Treatment delay and associated factors among adults with drug } \\
\text { resistant tuberculosis at treatment initiating centers in the Amhara regional state, Ethiopia. BMC infectious diseases. 2019; 19 (1): } \\
489 .\end{array}$ & 5 \\
\hline 25 & $\begin{array}{l}\text { Zeleke ZZ, Trifa ZM. Treatment delay among smear positive pulmonary tuberculosis patients in South Ethiopia: a cross-sectional } \\
\text { study. Science Journal of Public Health. 2014; } 2 \text { (5): 402-9. }\end{array}$ & 6 \\
\hline 26 & $\begin{array}{l}\text { Awoke N, Dulo B, Wudneh F. Total Delay in Treatment of Tuberculosis and Associated Factors among New Pulmonary TB Patients } \\
\text { in Selected Health Facilities of Gedeo Zone, Southern Ethiopia, 2017/18. Interdisciplinary perspectives on infectious diseases. } 2019 .\end{array}$ & 6 \\
\hline 27 & $\begin{array}{l}\text { Mesfin MM, Newell JN, Madeley RJ, Mirzoev TN, Tareke IG, Kifle YT, et al. Cost implications of delays to tuberculosis diagnosis } \\
\text { among pulmonary tuberculosis patients in Ethiopia. BMC Public Health. 2010;10: } 173\end{array}$ & 1 \\
\hline 28 & $\begin{array}{l}\text { Gebreegziabher SB, Bjune GA, Yimer SA. Total delay is associated with unfavorable treatment outcome among pulmonary } \\
\text { tuberculosis patients in west Gojjam zone, Northwest Ethiopia: a prospective cohort study. PloS one. 2016; } 11 \text { (7): e0159579. }\end{array}$ & 6 \\
\hline 29 & $\begin{array}{l}\text { Cambanis A, Yassin MA, Ramsay A, Bertel Squire S, Arbide I, Cuevas LE. Rural poverty and delayed presentation to tuberculosis } \\
\text { services in Ethiopia. Tropical Medicine \& International Health. } 2005 ; 10 \text { (4): 330-5. }\end{array}$ & 1 \\
\hline 30 & Gele AA, Bjune G, Abebe F. Pastoralism and delay in diagnosis of TB in Ethiopia. BMC public health. 2009; 9 (1): 5. & 6 \\
\hline 31 & $\begin{array}{l}\text { Tegegn A, Yazachew M. Delays in tuberculosis treatment and associated factors in Jimma Zone, Southwest Ethiopia. Ethiopian } \\
\text { Journal of Health Sciences. 2009; } 19 \text { (1). }\end{array}$ & 7 \\
\hline 32 & $\begin{array}{l}\text { Getnet F, Demissie M, Worku A, Gobena T, Tschopp R, Seyoum B. Longer Delays in Diagnosis and Treatment of Pulmonary } \\
\text { Tuberculosis in Pastoralist Setting, Eastern Ethiopia. Risk Management and Healthcare Policy. 2020; 13: } 583 \text {. }\end{array}$ & 7 \\
\hline 33 & $\begin{array}{l}\text { Mesfin MM, Tasew TW, Tareke IG, Kifle YT, Karen WH, Richard MJ. Delays and care seeking behavior among tuberculosis } \\
\text { patients in Tigray of northern Ethiopia. Ethiopian Journal of Health Development. 2005; } 19 \text { (I): } 7 .\end{array}$ & 8 \\
\hline 34 & $\begin{array}{l}\text { Wondimu T, Kassahun W, Getachew S. Delay in initiating tuberculosis treatment and factors associated among pulmonary } \\
\text { tuberculosis patients in East Wollega, Western Ethiopia. Ethiopian Journal of Health Development. 2007; } 21 \text { (2): 148-56. }\end{array}$ & 8 \\
\hline
\end{tabular}

Reasons for exclusion: 1 . only patient delay with or without its associated factors

2. Studies include children

3. Not related to the outcome variable

4. meta-analysis

5. Study done on MDR-TB patients

6. The outcome of interests was not reported

7. Different operational definition of health system delay

8. Do not report the IQR

Table 6. Associated factors reported by included studies on health system delay in the treatment of tuberculosis patients in Ethiopia.

\begin{tabular}{lll}
\hline Associated factors & Positive association & Preventive (Negative) association \\
\hline & Health center: $4.83(2.33-10.43)$ \\
& Clinic/health post: $19.70(6.18-62.79)$ \\
& Private facility: $2.49(1.07-5.84)$ \\
& [Belay et al] \\
& Health center: $5.1(2.1,12.5)$ \\
& Private: $3.5(1.3,9.7)$ \\
& Health post: $109(12,958)$ \\
& [Yimer et al] \\
& Health post $/$ private clinic/drug shop: $19.7(12.63-34.52)$ \\
& [Hussen et al] \\
& Health center: $1.3(1-1.9)$ \\
& Private clinic: $1.5(1-2.2)$ \\
& [Tedla et al] \\
EPTisit health facility $2.08(1.08-4.04)$ & [Belay et al]
\end{tabular}




\begin{tabular}{lll}
\hline Associated factors & Positive association & Preventive (Negative) association \\
\hline & Smear-negative PTB: $1.88(1.32-2.68)$ & \\
& [Gebregizaber et al] & House wife: $0.10(0.02-0.40)$ \\
[Gebregizaber et al] & Unemployed: 0.41 (0.24, 0.70$)$ \\
Occupation & & [Adenager et al] \\
& & Positive: $0.2(0.1,0.5)$ \\
HIV & & [Yimer et al]
\end{tabular}

\subsection{Subgroup Analysis}

In subgroup analyses, studies conducted with a sample size of less than 350 reports a pooled median health system delay of 16.34 (95\% CI: 6.33-26.34), Whereas, studies conducted with a sample size of more than 350 with a pooled median health system delay was 14.65 (95\% CI: 9.03-20.28) days. Based on the type of TB, studies that enrolled PTB patients had the highest pooled median health system delay $16.63(95 \%$ CI: 16.63 (7.46-25.81) days, followed by those studies that enrolled all forms of TB patients 16.01 (95\% CI: 6.02-26.01) days. Similarly, studies conducted from 1997 to 2015 reported the highest pooled median health system delay of $21.63(95 \%$ CI: 14.38-28.88) days as compared to studies conducted after 2015 with a pooled median time of 9.33 (95\% CI: 3.95-14.70) days (Table 2).

\subsection{Factors Associated with Health System Delay}

The data for each of the five associated factors were exported to Stata SE version 14 after extracting data on excel spread sheet. Ten studies [7, 9, 10, 35, 48-53] assessed associated factors including patients' socio-demographic characteristics, clinical characteristics, and diagnostic modalities. Six studies were analyzed the relationship between sex and health system delay; four studies assess distance to the health facility with health system delay. HIV serostatus was mentioned in three articles; from this one article mention that being HIV positive was decrease health system delay as compared to HIV negative patients [48]. Type of TB or form of TB mentioned in three articles and from these two articles showed that those who were smear- negative and EPTB patients had prolonged health system delay $[10,50]$ (Table 6). Three studies reported the association between residence and health system delay; one article revealed that patients living in the rural area had prolonged health system delay as compared to patients living in urban residences [35].

Our meta-analysis also showed that patients from the rural areas were more likely to have a prolonged health system delay with pooled OR of the studies (OR: 2.42, 95\%CI: 1.165.02). However, in our meta-analysis, there was no significant relationship between health system delay and distance from the health facility (OR: $1.36(0.72-2.55))$, form of TB (OR: 1.39 (0.99-1.95)), HIV serostatus (OR: 1.07 (0.82-1.39)) and sex (0.96 (0.80-1.15)) (Figure 2). Other socio-demographic and clinical as well as diagnostic modalities factors were not evaluated due to the lack of data in the individual studies.

\section{Discussion}

Even though a systemic review and meta-analysis done on patient delay in the diagnosis of tuberculosis patients in Ethiopia [55]; health system delays in the treatment of tuberculosis patients were not previously conducted. Thus, this meta-analysis attempted to estimate the pooled median health system delay and to review contextual factors associated with health system delay. The findings could be helpful for TB prevention and control programs; to effectively reducing delays for seeking prompt diagnosis and treatment. 
Stusy

10

ES $(95 \%$ C)

Weigh

\begin{tabular}{|c|c|c|}
\hline Belay et al (2010) & $0.95(0.51,1.7)$ & 25.43 \\
\hline Hyssen et al (2011) & $2.17(0.89,5.32)$ & 20.08 \\
\hline Habroo ef at (2017) & $2.65(1.39,5.04)$ & 24.85 \\
\hline yimet et al $(2003)$ & $0.76(0.51,1.14)$ & 29.53 \\
\hline Crerall (p-squared $=76.4 \%, p=0.005$ ) & $1.36(0.72,2.55)$ & 10000 \\
\hline NOTE: Weights are fom random efects analyvis & & \\
\hline 1 & 10 & \\
\hline
\end{tabular}

a

stopy

-

es $\cos S C D$

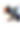

Weve

98

$1.05(066.167)$

324

$1 \times 002220$

27 es

$1.07(0.82,1.39)$

10000

Nort: Weghts are troen randoen etelects anarsis 
Study

D

ES (95\% C)

Belay et al (2010)

Gebreegizaber et al (2017)

jieme et al (2010)

Hussen at al (2011)

Adenager et al (2012)

jimet et al (2003)

Orerall (p-squared $=0.0 \%, p=0.49 \mathrm{M})$

NOTE: Weights are from random effects analysis

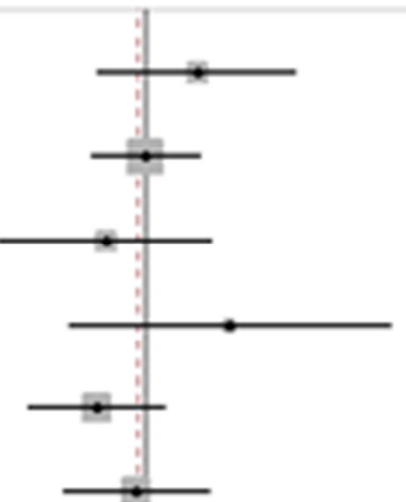

$1.33(0.76,2.31) \quad 10.52$

$1.00(0.74,1.35) \quad 35.12$

$0.80(0.44,1.45) \quad 9.11$

$1.59(0.65,3.90) \quad 4.02$

$0.76(0.52,1.12) \quad 21.77$

$0.95(0.63,1.43) \quad 19.47$

$0.96(0.80,1.15) \quad 100.00$
Study

o

yieme et al (2010)

Asires ot al (2016)

Balay et al (2010)

Owrall (p-squared $=23.9 \%, p=0.245$ )

NOTE: Weights are foem ransom etects analysis
\%

ES $(95 \% \mathrm{C})$

Weigh

\begin{tabular}{|c|c|c|}
\hline yiemr et al (2010) & $1.20(0.65,221)$ & 23.83 \\
\hline Asires et al (2016) & $1.20(0.84,1.72)$ & 49.18 \\
\hline Baloy et al (2010) & $2.08(1,18,3,66)$ & 26.99 \\
\hline Owerall (p-squared $=23.9 \%, p=0.245$ ) & $1.39(0.99,1.95)$ & 10000 \\
\hline NOTE: Weights are fom random efects analysis & & \\
\hline $\begin{array}{l}1 \\
1\end{array}$ & 10 & \\
\hline
\end{tabular}




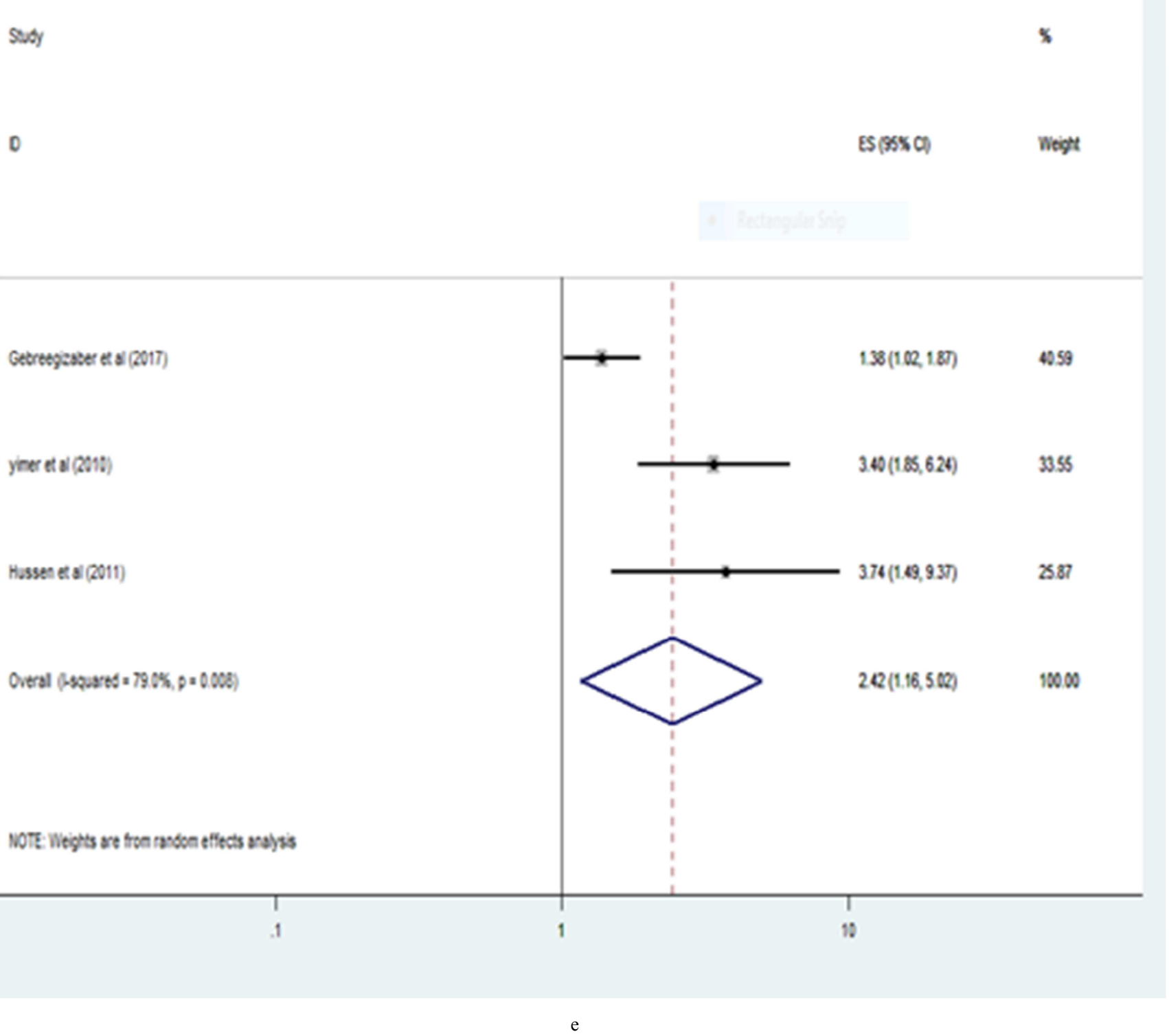

Figure 2. Forest plots of meta-analysis of factors associated with health system delay among TB patients in Ethiopia. This figure shows forest plots for the meta-analysis of five factors associated with health system delay. Notes: A-distance; B-HIV; C-Sex; D-type of TB and E-Residence.

Our finding showed that the pooled median health system delay in the treatment of tuberculosis patients was $15.29(95 \%$ CI: 9.94-20.64) days. These results suggest that even when patients seek care in a timely manner, significant time can be lost after their first contact with the healthcare provider. Our pooled analysis also indicated that residence was significantly associated with health system delay. Patients from rural residences were more likely to delay in the treatment of tuberculosis compared to those patients from urban areas (pooled $\mathrm{OR}=2.42 ; 95 \% \mathrm{CI}=1.16-5.02$ ). This might be due to the fact that, access to health care services was particularly low in rural areas of Ethiopia where the majority of the population lives. Together with uneven distribution of health care professionals, results in little availability and poor quality of health care services in rural areas [56].

Our finding showed that the pooled median health system delay was lower as compared to the previous systematic review and meta-analysis done in LMIC, estimated average health system delay was 28.4 days [24], India the pooled median health system delay was 31 days [22], and a systematic review done in 78 countries, the pooled health system delay was 39.3 days [57]. This finding also lower than primary studies done in Vietnam 42 days [26], Taiwan 29 days [58], China 26 days [59], and Turkey 64.1 days [60]. The possible reasons for such discrepancy might be related to differences in the accessibility of health care service or variation of the infrastructure from country to country and it could be also due to improvements in the diagnostic capacities like the introduction of rapid molecular diagnostic tests especially, Gene Xpert technology which effectively shortened the health system delays [34, 61]. Our finding was in line with studies conducted in Hong Kong 20 days [62] and Nepal 18 days [33]. However, the pooled estimate median health system delay was higher than studies done in Vietnam 7 days [26], China 4 days [63], and Uzbekistan 7 days [64]. This might be due to the high costs variation 
especially for the diagnosis of EPTB patients for pathological and $\mathrm{X}$-ray diagnosis which were not free of a charge unlike the rest of TB services. Secondly, it might be due to the difference in our inclusion criterion regarding included studies dates of publication, study participants, and types of TB. Our systematic review and meta-analysis enrolled both PTB and EPTB but the above studies only include smearpositive PTB patients. Since smear-negative PTB and EPTB patients might be need a number of investigations that would be requested before confirming the diagnosis which might be leads to prolong the health system delay $[32,65]$. The other possible explanation could be due to having poor access and low health care service coverage, a study was done in Ethiopia showed that, the overall TB health care service coverage was $23 \%$ [66].

Our findings, in the subgroup analysis suggested that, studies conducted from 1997 to 2015 had the highest pooled median health system delay of 21.63 (95\% CI: 14.38-28.88) days as compared to studies conducted after 2015 with a pooled median health system delay of 9.33 (95\% CI: 3.9514.70) days. This might be due to the establishment of the End TB strategy. Since it starts after 2015, and the main targets were $90 \%$ reduction in TB deaths and minimize TB incidence by $80 \%$ in 2030 . To achieve this goal WHO sets as one of the main strategy was through early diagnosis and prompt treatment [5]. Therefore, to reduce the time delay for diagnosis and treatment of tuberculosis patients, WHO recommended rapid molecular diagnostic tests such as Xpert ${ }^{\circledR}$ MTB/RIF assay. Xpert provide results within 2 hours, this leads to a significant impact on reducing health system delay [5]. Furthermore, the national TB program of Ethiopia has also re-prioritized the key strategic interventions in the five-year national TB strategic plan that paves towards achieving to reach $90 \%$ of all people with tuberculosis diagnosed and treated [1]. The program is committed to improve access and equitable TB services to vulnerable and marginalized population groups where TB burden concentrates and most delays happen. In addition, the program also considered that the strategies could only be achieved if TB diagnosis, treatment, and prevention services are provided within the context of progressing towards universal health coverage [30]. This program-related consideration might be the contributing factor for the reduction of a pooled median health system delay for studies conducted after 2015 in Ethiopia.

In this systematic review and meta-analysis, we found that rural residence had a positive association with health system delay. Being from the rural residents were nearly two and half times more likely to delay in the treatment of tuberculosis compared to those patients from urban residents with a pooled OR of 2.42 (95\% CI: 1.16-5.02). The finding of this review was consistent with a systematic review and meta-analysis done in 40 countries [23]. Similarly, this finding was supported by primary studies conducted in Tajikistan [67], India [68], Indonesia [69], and China [63]. The possible plausible reason for this situation could be patients living in rural areas had low access to health care facilities, as a result of the absence of better access to anti-tuberculosis drugs and diagnostic modalities [70]. For instance, most patients in rural areas of Ethiopia had primary access to the health post (first level of the health care system) where there were no TB diagnostic services [48], and patients might walk for some hours to access hospitals or health centers [71]. The other possible explanation might be, $85 \%$ of the rural population of Ethiopia not having access to health care, and lack of physicians available in the public sectors. As well as, appropriate and affordable TB services is still problematic in some rural areas of Ethiopia [7274] that could lead to prolonged health system delay. In addition to this, initially those patients were come from rural residents repeatedly visited traditional healers before diagnosis and treatment [75]. Many patients from rural areas did not arrive at the health care facilities on time unless they were seriously sick [71]. Since, the presence of traditional healers, which are prominent in rural areas across developing countries had been suggested that seeing traditional healers influence tuberculosis treatment initiation [76]. A study conducted in a rural area of China, Tanzania, and South Africa showed that visiting traditional healers were significantly associated with health system delay $[59,76,77]$. Therefore, this may lead to longer health system delay.

In this systematic review and meta-analysis, distance from the health facility, HIV status, sex, and type of TB were not associated with the health system delay. Even though a number of included studies were reported that distance from the health facility more likely to lead prolonged health system delay, the pooled analysis indicated that distance from the health facility was not associated with health system delay. The possible explanation might be since health system delay starts from when the patients reach at the health care provider, factors which were related to the health system delay mainly related to health care system related factors or factors which drive within the health care system like a lack of availability of trained man-power and diagnostic modality services might be leads to prolonged health system delay [33].

\section{Limitations}

Our search strategy was rigorous and multiple sources were searched, and we obtain studies from all regions of Ethiopia, this allows the study to represent the burden of health system delay at the national level. Despite these, our systematic review and meta-analysis was not free from limitations that arose from either individual studies or the review process. The review was limited to only articles published in the English language, and all included studies were cross-sectional studies. Since cross-sectional studies had a number of inherent limitations that potentially bias the results, and lack of the ability to determine causality as do other observational studies. The other limitation, since WHO as well as Ethiopia at the national level had no cut-off point to say tuberculosis patients were delayed or not. Due to this, each included study had a different cut-off point and they were not directly suited for a meta-analysis. Rather than excluding studies that failed to meet strict criteria, we tried to extract all the studies to arrive at a 
more national understanding of factors contributing to the health system delay.

\section{Conclusion}

In Ethiopia, this review highlights that patients were delayed more than two weeks in the treatment of tuberculosis. Being a rural resident, was the contributing factor of health system delay. This finding sound that TB patients were waited too long time to initiate anti-TB treatment and this might increase the morbidity and mortality of tuberculosis patients. Furthermore, the extended delays in these patients reflecting that, since they were visiting the health care system; health care providers could pose a greater risk of disease transmission and the community at large. Therefore, this suggests that there need to be strengthen early diagnosis, and treatment strategies on tuberculosis mainly to the rural residents through availing the scaling up of rapid molecular diagnostic tests such as Gene expert, improving access to DOTS services, and enhancing the capacity of health care providers on tuberculosis in rural areas could be vital. These could be an effective strategy to overcome the barriers of health system delay and critical to interrupt transmission of this deadly disease in the country. For successful TB control, implementing efforts like providing regular health education to the community about TB emphasizes the rural community and enhancing the quality of care in $\mathrm{TB}$ treatment facilities in rural areas could have important implications to reduce health system delay. The information provided by this review could assist health policy-makers in devising suitable interventions in order to minimize health system delay and reduce transmission of infection in the community.

\section{Abbreviations}

DOTs: Directly Observed Treatment, Short-Course; EPTB: Extra Pulmonary Tuberculosis; HIV: Human Immunodeficiency Virus; IQR: Inter Quartile Range; MDR TB: Multi Drug Resistance Tuberculosis; PRISMA: Preferred Reporting Items for Systematic Reviews and Meta-Analysis; PTB: Pulmonary Tuberculosis; TB: Tuberculosis; WHO: World health Organization

\section{Competing Interests}

The authors declare that they have no competing interests.

\section{Authors' Contributions}

KT and FW: originated the research idea, literature review, data extraction, data analysis, interpretation and drafting the manuscript. YAB, DE and DB: contribute on data extraction, quality assessment, data analysis and manuscript review, edition \& validation. All authors have read and approved the manuscript.

\section{Acknowledgements}

The authors of this work would like to forward great and deepest gratitude for Debre Markos University for creating convenient environment and internet service. Furthermore, the authors would like also to forward special acknowledgement for authors of primary studies.

\section{References}

[1] FMOH. Guideline for management of TB, DR-TB and LeprosyinEthiopia. 2018.

[2] WHO. Global Tuberculosis report. Executive summary2020.

[3] WHO. Global Tuberculosis report. 2020.

[4] Anochie P. How to control the Tuberculosis and HIV/AIDS dual epidemic. Archives of Community Medicine \& Public Health. 2015: 026-37.

[5] WHO. GlobalTuberculosis report. 2017.

[6] WHO. Global Tuberculosis report. 2019.

[7] Yimer S, Bjune G, Alene G. Diagnostic and treatment delay among pulmonary tuberculosis patients in Ethiopia: a cross sectional study. BMC infectious diseases. 2005; 5 (1): 112.

[8] Asefa A, Teshome W. Total delay in treatment among smear positive pulmonary tuberculosis patients in five primary health centers, southern Ethiopia: a cross sectional study. PloS one. 2014; 9 (7): e102884.

[9] Asres A, Jerene D, Deressa W. Delays to treatment initiation is associated with tuberculosis treatment outcomes among patients on directly observed treatment short course in Southwest Ethiopia: a follow-up study. BMC pulmonary medicine. 2018; 18 (1): 1-11.

[10] Belay M, Bjune G, Ameni G, Abebe F. Diagnostic and treatment delay among Tuberculosis patients in Afar Region, Ethiopia: a cross-sectional study. BMC public health. 2012; 12 (1): 1-8.

[11] Ayalew YE, Yehualashet FA, Bogale WA, Gobeza MB. Delay for Tuberculosis Treatment and Its Predictors among Adult Tuberculosis Patients at Debremarkos Town Public Health Facilities, North West Ethiopia. Tuberculosis research and treatment. 2020; 2020.

[12] Organization WH. Diagnostic and treatment delay in tuberculosis. 2006.

[13] foundation BMg. Exploring TB care and control within the EthiopianHealth care system; country Assessment. 2016.

[14] Dharmadhikari AS, Mphahlele M, Venter K, Stoltz A, Mathebula R, Masotla T, et al. Rapid impact of effective treatment on transmission of multidrug-resistant tuberculosis. The International journal of tuberculosis and lung disease. 2014; 18 (9): 1019-25.

[15] Kipiani M, Mirtskhulava V, Tukvadze N, Magee M, Blumberg HM, Kempker RR. Significant Clinical Impact of a Rapid Molecular Diagnostic Test (Genotype MTBDR plus Assay) to Detect Multidrug-Resistant Tuberculosis. Clinical infectious diseases. 2014; 59 (11): 1559-66. 
[16] Madebo T, Lindtjorn B. Delay in treatment of pulmonary tuberculosis: an analysis of symptom duration among Ethiopian patients. MedGenMed: Medscape general medicine. 1999: E6.

[17] Golub J, Bur S, Cronin W, Gange S, Baruch N, Comstock G, et al. Delayed tuberculosis diagnosis and tuberculosis transmission. The international journal of tuberculosis and lung disease. 2006; 10 (1): 24-30.

[18] Virenfeldt J, Rudolf F, Camara C, Furtado A, Gomes V, Aaby $P$, et al. Treatment delay affects clinical severity of tuberculosis: a longitudinal cohort study. BMJ open. 2014; 4 (6).

[19] Farah MG, Rygh JH, Steen TW, Selmer R, Heldal E, Bjune G. Patient and health care system delays in the start of tuberculosis treatment in Norway. BMC infectious diseases. 2006; 6 (1): 33 .

[20] Chiang CY, Chang C, Chang R, Li C, Huang R. Patient and health system delays in the diagnosis and treatment of tuberculosis in Southern Taiwan. The international journal of tuberculosis and lung disease. 2005; 9 (9): 1006-12.

[21] Getnet F, Demissie M, Assefa N, Mengistie B, Worku A. Delay in diagnosis of pulmonary tuberculosis in low-and middle-income settings: systematic review and meta-analysis. BMC pulmonary medicine. 2017; 17 (1): 202.

[22] Sreeramareddy CT, Qin ZZ, Satyanarayana S, Subbaraman R, Pai M. Delays in diagnosis and treatment of pulmonary tuberculosis in India: a systematic review. The International Journal of Tuberculosis and Lung Disease. 2014; 18 (3): 25566.

[23] Storla DG, Yimer S, Bjune GA. A systematic review of delay in the diagnosis and treatment of tuberculosis. BMC public health. 2008; 8 (1): 15.

[24] Sreeramareddy CT, Panduru KV, Menten J, Van den Ende J. Time delays in diagnosis of pulmonary tuberculosis: a systematic review of literature. BMC infectious diseases. 2009; 9 (1): 91.

[25] Ohmori M, Ozasa K, Mori T, Wada M, Yoshiyama T, Aoki M, et al. Trends of delays in tuberculosis case finding in Japan and associated factors. The International Journal of Tuberculosis and Lung Disease. 2005; 9 (9): 999-1005.

[26] Huong NT, Vree M, Duong BD, Khanh VT, Loan VT, Borgdorff MW, et al. Delays in the diagnosis and treatment of tuberculosis patients in Vietnam: a cross-sectional study. BMC public health. 2007; 7 (1): 110.

[27] Sabawoon W, Sato H, Kobayashi Y. Delay in the treatment of pulmonary tuberculosis: a report from Afghanistan. Environmental health and preventive medicine. 2012; 17 (1): 53-61.

[28] Takarinda KC, Harries AD, Nyathi B, Ngwenya M, MutasaApollo T, Sandy C. Tuberculosis treatment delays and associated factors within the Zimbabwe national tuberculosis programme. BMC public health. 2015; 15 (1): 29.

[29] Kansiime C, Kiwuwa SM, Levi M, Asiimwe BB, Katamba A. Health service delay among pulmonary tuberculosis patients presenting to a National Referral Hospital, Kampala, Uganda: a cross sectional study. Pan African Medical Journal. 2013; 15 (1).
[30] Organization WH. The global plan to stop TB 2011-2015: transforming the fight towards elimination of tuberculosis. 2010 .

[31] Saifodine A, Gudo PS, Sidat M, Black J. Patient and health system delay among patients with pulmonary tuberculosis in Beira city, Mozambique. BMC public health. 2013; 13 (1): 559.

[32] Makwakwa L, Sheu M-1, Chiang C-Y, Lin S-L, Chang PW. Patient and health system delays in the diagnosis and treatment of new and retreatment pulmonary tuberculosis cases in Malawi. BMC infectious diseases. 2014; 14 (1): 132.

[33] Basnet R, Hinderaker SG, Enarson D, Malla P, Mørkve O. Delay in the diagnosis of tuberculosis in Nepal. BMC public health. 2009; 9 (1): 236.

[34] Cox HS, Mbhele S, Mohess N, Whitelaw A, Muller O, Zemanay W, et al. Impact of Xpert MTB/RIF for TB diagnosis in a primary care clinic with high TB and HIV prevalence in South Africa: a pragmatic randomised trial. PLoS Med. 2014; 11 (11): e1001760.

[35] Hussen A, Biadgilign S, Tessema F, Mohammed S, Deribe K, Deribew A. Treatment delay among pulmonary tuberculosis patients in pastoralist communities in Bale Zone, Southeast Ethiopia. BMC research notes. 2012; 5 (1): 320.

[36] Sullivan BJ, Esmaili BE, Cunningham CK. Barriers to initiating tuberculosis treatment in sub-Saharan Africa: a systematic review focused on children and youth. Global health action. 2017; 10 (1): 1290317.

[37] Eltayeb D, Pietersen E, Engel M, Abdullahi L. Factors associated with tuberculosis diagnosis and treatment delays in Middle East and North Africa: a systematic review. Eastern Mediterranean Health Journal. 2020; 26 (4): 477-86.

[38] Finnie RK, Khoza LB, van den Borne B, Mabunda T, Abotchie P, Mullen PD. Factors associated with patient and health care system delay in diagnosis and treatment for TB in sub-Saharan African countries with high burdens of TB and HIV. Tropical medicine \& international health. 2011; 16 (4): 394-411.

[39] Uplekar M, Organization WH. The Stop TB Strategy: building on and enhancing DOTS to meet the TB-related Millennium Development Goals. World Health Organization; 2006.

[40] David Moher AL, Jennifer Tetzlaff, Douglas G. Altman, The PRISMA Group. Preferred Reporting Items for Systematic Reviews and Meta-Analyses: The PRISMA Statement. PLoS Medicine. 2009.

[41] https://en.wikipedia.org/wiki/Ethiopia

[42] WHO. Diagnostic and treatment delay in Tuberculosis. An indepth analysis of the health-seeking behaviour of patients and health system response in seven countries of the Eastern Mediterranean Region; 2006.

[43] Newcastle O. Newcastle-Ottawa: Scale customized for crosssectional studies In available from https: //staticcontent.springer.com/esm/.../12889_2012_5111_ MOESM3 ESM.doc. 2018.

[44] Herzog R, Álvarez-Pasquin MJ, Díaz C, Del Barrio JL, Estrada JM, Gil Á. Are healthcare workers' intentions to vaccinate related to their knowledge, beliefs and attitudes? A systematic review. BMC public health. 2013; 13 (1): 154. 
[45] Tekelab T, Chojenta C, Smith R, Loxton D. Factors affecting utilization of antenatal care in Ethiopia: A systematic review and meta-analysis. PloS one. 2019; 14 (4): e0214848.

[46] Higgins JP, Thompson SG, Deeks JJ, Altman DG. Measuring inconsistency in meta-analyses. Bmj. 2003; 327 (7414): 55760 .

[47] Bogale S, Diro E, Shiferaw AM, Yenit MK. Factors associated with the length of delay with tuberculosis diagnosis and treatment among adult tuberculosis patients attending at public health facilities in Gondar town, Northwest, Ethiopia. BMC infectious diseases. 2017; 17 (1): 145.

[48] Yimer SA, Bjune GA, Holm-Hansen C. Time to first consultation, diagnosis and treatment of TB among patients attending a referral hospital in Northwest, Ethiopia. BMC infectious diseases. 2014; 14 (1): 19.

[49] Seid A, Metaferia Y. Factors associated with treatment delay among newly diagnosed tuberculosis patients in Dessie city and surroundings, Northern Central Ethiopia: a cross-sectional study. BMC Public Health. 2018; 18 (1): 1-13.

[50] Gebreegziabher SB, Bjune GA, Yimer SA. Patients' and health system's delays in the diagnosis and treatment of new pulmonary tuberculosis patients in West Gojjam Zone, Northwest Ethiopia: a cross-sectional study. BMC infectious diseases. 2016; 16 (1): 1-13.

[51] Tedla K, Medhin G, Berhe G, Mulugeta A, Berhe N. Factors associated with treatment initiation delay among new adult pulmonary tuberculosis patients in Tigray, Northern Ethiopia. PloS one. 2020; 15 (8): e0235411.

[52] Haboro G, Handiso T, Gebretsadik L. Health care system delay of tuberculosis treatment and its correlates among pulmonary tuberculosis patients in Hadiya Zone public health facilities, Southern Ethiopia. Journal of Infectious Diseases and Epidemiology. 2019; 5 (2): 1-6.

[53] Adenager GS, Alemseged F, Asefa H, Gebremedhin AT. Factors associated with treatment delay among pulmonary tuberculosis patients in public and private health facilities in Addis Ababa, Ethiopia. Tuberculosis research and treatment. $2017 ; 2017$.

[54] Datiko DG, Jerene D, Suarez P. Patient and health system delay among TB patients in Ethiopia: Nationwide mixed method cross-sectional study. BMC Public Health. 2020; 20 (1): $1-10$.

[55] Alene M, Assemie MA, Yismaw L, Gedif G, Ketema DB, Gietaneh W, et al. Patient delay in the diagnosis of tuberculosis in Ethiopia: a systematic review and metaanalysis. BMC infectious diseases. 2020; 20 (1): 1-9.

[56] Bilal NK, Herbst CH, Zhao F, Soucat A, Lemiere C. Health extension workers in Ethiopia: improved access and coverage for the rural poor. Yes Africa Can: Success Stiroes from a Dynamic Continent. 2011: 433-43.

[57] Bello S, Afolabi RF, Ajayi DT, Sharma T, Owoeye DO, Oduyoye $\mathrm{O}$, et al. Empirical evidence of delays in diagnosis and treatment of pulmonary tuberculosis: systematic review and meta-regression analysis. BMC public health. 2019; 19 (1): 820 .

[58] Chen C-C, Chiang C-Y, Pan S-C, Wang J-Y, Lin H-H. Health system delay among patients with tuberculosis in Taiwan: 2003-2010. BMC infectious diseases. 2015; 15 (1): 491.
[59] Verhagen L, Kapinga R, van Rosmalen-Nooijens K. Factors underlying diagnostic delay in tuberculosis patients in a rural area in Tanzania: a qualitative approach. Infection. 2010; 38 (6): 433-46.

[60] Güneylioglu D, Yilmaz A, Bilgin S, Bayram U, Akkaya E. Factors affecting delays in diagnosis and treatment of pulmonary tuberculosis in a tertiary care hospital in Istanbul, Turkey. Medical Science Monitor. 2004; 10 (2): CR62-CR7.

[61] Yoon C, Cattamanchi A, Davis JL, Worodria W, den Boon S, Kalema N, et al. Impact of Xpert MTB/RIF testing on tuberculosis management and outcomes in hospitalized patients in Uganda. PloS one. 2012; 7 (11): e48599.

[62] Leung EC, Leung C, Tam C. Delayed presentation and treatment of newly diagnosed pulmonary tuberculosis patients in Hong Kong. Hong Kong Medical Journal. 2007; 13 (3): 221.

[63] Lin X, Chongsuvivatwong V, Geater A, Lijuan R. The effect of geographical distance on TB patient delays in a mountainous province of China. The International Journal of Tuberculosis and Lung Disease. 2008; 12 (3): 288-93.

[64] Belkina TV, Khojiev DS, Tillyashaykhov MN, Tigay ZN, Kudenov MU, Tebbens JD, et al. Delay in the diagnosis and treatment of pulmonary tuberculosis in Uzbekistan: a crosssectional study. BMC infectious diseases. 2014; 14 (1): 624.

[65] Jurcev-Savicevic A, Mulic R, Kozul K, Ban B, Valic J, BacunIvcek L, et al. Health system delay in pulmonary tuberculosis treatment in a country with an intermediate burden of tuberculosis: a cross-sectional study. BMC public health. 2013; 13 (1): 250

[66] Asemahagn MA, Alene GD, Yimer SA. Geographic Accessibility, Readiness, and Barriers of Health Facilities to Offer Tuberculosis Services in East Gojjam Zone, Ethiopia: A Convergent Parallel Design. Research and Reports in Tropical Medicine. 2020; 11: 3 .

[67] Ayé R, Wyss K, Abdualimova H, Saidaliev S. Patient's site of first access to health system influences length of delay for tuberculosis treatment in Tajikistan. BMC health services research. 2010; 10 (1): 10.

[68] Rajeswari R, Chandrasekaran V, Suhadev M, Sivasubramaniam S, Sudha G, Renu G. Factors associated with patient and health system delays in the diagnosis of tuberculosis in South India. The International Journal of Tuberculosis and Lung Disease. 2002; 6 (9): 789-95.

[69] Mahendradhata Y, Syahrizal BM, Utarini A. Delayed treatment of tuberculosis patients in rural areas of Yogyakarta province, Indonesia. BMC public health. 2008; 8 (1): 1-6.

[70] Zhang T, Tang S, Jun G, Whitehead M. Persistent problems of access to appropriate, affordable TB services in rural China: experiences of different socio-economic groups. BMC public health. 2007; 7 (1): 19.

[71] Tadesse T, Demissie M, Berhane Y, Kebede Y, Abebe M. Long distance travelling and financial burdens discourage tuberculosis DOTs treatment initiation and compliance in Ethiopia: a qualitative study. BMC public health. 2013; 13 (1): 424.

[72] Hibbett K. ADDRESSING THE BARRIERS TO PROPER HEALTH CARE IN ETHIOPIA. 2018.

[73] WHO. World health report. shaping the future2003. 
[74] Rural Development Strategy Review of Ethiopia (Internet). 2020.

[75] Yamasaki-Nakagawa M, Ozasa K, Yamada N, Osuga K, Shimouchi A, Ishikawa N, et al. Gender difference in delays to diagnosis and health care seeking behaviour in a rural area of Nepal. The International Journal of Tuberculosis and Lung Disease. 2001; 5 (1): 24-31.

[76] Barker R, Millard F, Malatsi J, Mkoana L, Ngoatwana T,
Agarawal S, et al. Traditional healers, treatment delay, performance status and death from TB in rural South Africa. The International Journal of Tuberculosis and Lung Disease. 2006; 10 (6): 670-5.

[77] Bai L-Q, Xiao S-Y. Factors associated with diagnostic delay for patients with smear-positive pulmonary tuberculosis in rural Hunan, China. Zhonghua jie he he hu xi za zhi= Zhonghua jiehe he huxi zazhi $=$ Chinese journal of tuberculosis and respiratory diseases. 2004; 27 (9): 617-20. 